\title{
Tourism and ICT Solutions in the COVID-19 Era: A Comparison Between Japan and Sweden
}

\author{
Akira Ide ${ }^{1}$ \\ Received: 4 October 2020 / Accepted: 19 February 2021 / Published online: 19 April 2021 \\ (c) Springer Japan KK, part of Springer Nature 2021
}

\begin{abstract}
Due to the spread of the new coronavirus (COVID-19), the tourism industry has been experiencing a worldwide crisis. However, the effects of the virus differ widely across regions and countries, and the current situation varies considerably. In this study, I will discuss the difficulties faced by the tourism industry regarding the new coronavirus by comparing Japan and Sweden, focusing on discrimination in the tourism industry. In Japan, discrimination based on place of residence has been observed, while in Sweden, race-based discrimination has been confirmed. Considering the current situation, we will examine how information and communication technology (ICT) can be used to salvage the tourism industry in each country. Specifically, we propose a method to increase the sense of security of guests and hosts in the tourism industry through many types of location-based games, such as Pokémon Go and various contact tracing apps. This study is expected to foster trust in the tourism and service industries and bring about business innovation.
\end{abstract}

Keywords Tourism · Covid-19 · Discrimination · Location-based game $\cdot$ Contact tracing

\section{Introduction}

Coronavirus disease 2019 (COVID-19) has surprised global society with its severity. This new disease has drastically changed society, community, and daily life. The impact on the tourism industry has been substantial because many countries have closed their borders and applied considerable restrictions to the movement of people. In this paper, we compare the impacts of COVID-19 on the tourism industries in Japan and Sweden. We also consider how COVID-19 has caused incidents of discrimination at tourist sites, and investigate tourism as a means of globally enhancing mutual understanding and cultural exchange. Furthermore, we explore the use

Akira Ide

akiraide@gakushikai.jp

1 Kanazawa University, Kanazawa, Japan 
of information and communication technology (ICT) to eliminate ethnicity-based discrimination at tourist sites and to revive the tourism industry during and after the COVID-19 pandemic.

The purpose of this paper was to explore the possibility of avoiding discrimination with ICT, assuming that it is currently occurring in both Japan and Sweden. This study is not intended to prove the occurrence of discrimination. Current information on the present situation regarding discrimination relies on the press. However, even if the phenomena appear the same on the surface, the logical structures that cause problems are different in each country. Therefore, based on the methodology of regionology, we will use the press to investigate situations in each region and inductively show that the social structure are be different.

\section{Tourism Industry in Japan}

\subsection{Japanese Tourism Industry before and after COVID-19}

Before describing Japanese tourism during the COVID-19 era, we provide an overview of the status based on data in 2019, prior to the pandemic. Thus far, the Japanese government has asked residents and businesses to refrain voluntarily from normal activities, in an effort to prevent the spread of COVID-19. Strong social pressure has been sufficient for many business entities and residents to follow this request for self-restraint.

Notably, there are no established legal sanctions or punishments for failure to follow the request for reduced activities. Therefore, the government has not collected data regarding the numbers of closed shops and restaurants, the numbers of residents who have stayed home, or the numbers of residents who have worked from home. Requests for closure of shops and restaurants have been relatively lenient and considerably vague; for example, restaurants have been allowed to remain open until 8 p.m., but alcoholic beverages can only be served until 7 p.m. Because of these lenient restrictions, there are no precise data concerning closed restaurants and shops.

Despite the absence of official statistical data, there have been some reports regarding self-restraint on the part of many shops and restaurants in local shopping areas, based on orders issued by local business associations[1]. ${ }^{1}$ Based on those local reports, we can see the self-restraint situation somewhat. In this paper, we examine Japanese tourism with the assumption that many commercial activities have been suspended because of the COVID-19 pandemic.

\footnotetext{
1 The reason why the Japanese government does not collect accurate data on restaurant closures is that it only asks for restaurant and store closures, not by force but by request. Therefore, the government has no intention of gathering statistics because each store is free to refuse to comply with the request.
} 


\subsection{Inbound Tourism}

Japanese tourism was not regarded as an economic engine in the twentieth century, particularly with regard to inbound tourism. For many years, the Japanese economy has demonstrated chronic export surpluses, which accelerated in the 1980s [2]. Therefore, the Japanese government encouraged residents to travel abroad to rectify the trade imbalance. This caused a rapid increase in the number of the people travelling abroad; for example, more than 5 million and 10 million people traveled overseas in 1986 and 1990, respectively. Although the numbers of people going abroad temporarily decreased following the terrorist attacks on the United States in 2001 and the severe acute respiratory syndrome outbreak in China in 2003, they have been steadily increasing overall. Data in 2019 indicated that these numbers were eventually likely to exceed 20 million $[3,4]$.

Importantly, a major shift in inbound tourism began in the early twenty-first century. In 2003, the number of inbound tourists to Japan was approximately 5.2 million, which was much lower than the number of Japanese people traveling abroad. At that time, Japanese Prime Minister Junichiro Koizumi launched the Yokoso Japan (Welcome to Japan) campaign, which was promoted internationally. After this campaign, tourism came to be recognized as an important means of acquiring foreign currency, rather than as a means of rectifying the trade imbalance. The campaign continued after the transition to a new government in Japan, and the number of foreign visitors steadily increased until the COVID-19 pandemic. This was not permanently affected by the aftermath of the Lehman Brothers' collapse of 2008 and the Great East Japan Earthquake of 2011. In 2013, the number of foreign visitors exceeded 10 million for the first time in history. It then exceeded 20 million in 2016 and 30 million in 2018 [4]. In 2020, Japan had been scheduled to host the Summer Olympic Games in Tokyo. Accordingly, Prime Minister Shinzo Abe expected to have 40 million foreign visitors to Japan in 2020, prior to the onset of the COVID19 pandemic.

After the COVID-19 pandemic spread worldwide, the number of inbound visitors to Japan decreased to about 2,900 in April 2020, which was 99.9\% lower than the number in April 2019. Furthermore, the estimated number of tourist visitors was 776, which was nearly 100\% lower than in April 2019 [5]. The data show that inbound tourism has been severely impacted by the COVID-19 pandemic. This paper discusses the need for research regarding revival of the Japanese tourism industry without the influx of foreign tourists.

\subsection{Domestic Tourism in Japan}

As mentioned above, inbound tourism in Japan experienced catastrophic damage from the COVID-19 pandemic. However, Japanese domestic tourism has always been mainly supported by Japanese residents. Although foreign visitors have had greater travel expenses since 2011, the proportion of travel expenses by foreign visitors to Japan comprised approximately 15\% of the total travel expenses (about 260 
billion US \$) in 2017. This indicates that the main engine of the Japanese tourism market involves domestic consumption by Japanese people.

Importantly, the Japan Tourism Agency announced that domestic travel was reduced by $96.6 \%$ in May 2020, compared to May 2019. This indicates that domestic tourism was critically damaged, in a manner similar to that of inbound tourism. However, domestic tourism is presumably less affected by border closures, compared to inbound tourism. The availability of a mechanism to encourage travel by Japanese people might aid in reviving domestic tourism.

On 10 July 2020, the Japanese government announced a new official domestic tourism campaign, Go To Travel, which was planned for implementation in late July. When people book domestic travel through certain websites or travel agencies promoting the campaign, the government would subsidize up to $50 \%$ of the travel expense.

However, many people were diagnosed with COVID-19 in the urban area of Tokyo, shortly before implementation of the campaign. Accordingly, on 16 July 2020, the government excluded the Tokyo area from the campaign. Therefore, people who desire benefits from the campaign are likely to plan travel to rural areas. Although this campaign brings domestic tourists and economic benefit to rural areas, there is substantial concern that tourists might bring COVID-19 to rural areas. In some of these rural areas, fear of COVID-19 has led to discrimination against people from other regions. As detailed in 3.1, rural residents' fear of tourists from the city could be intense because it was recognized that the disease spread from the city to the countryside. For example, tourists who travel to rural areas using their own vehicles can be identified by their license plates. In Japan, license plates show the region that has issued the license number [6]. Therefore, local residents can easily identify tourists. Recognized tourists might be refused entry to local businesses, or might experience damage to their vehicles. Accordingly, local communities protect themselves against COVID-19 and the local residents actively exclude tourists.

In this context, it is difficult to manage tourism in rural areas. While some local businesses are eager to attract tourists, the nearby residents have a fear of these individuals who might be affected by COVID-19.

\section{Tourism in Sweden}

\subsection{COVID-19 Pandemic in Sweden}

In this section, we describe the overall state of Swedish tourism during the COVID19 pandemic. Sweden is one of the few countries where a nationwide lockdown was not applied during the COVID-19 pandemic. According to Swedish national epidemiologists and the Public Health Agency of Sweden, Sweden adopted the most suitable approach for Swedish citizens and Swedish society. Their strategy was simple: people voluntarily followed social distancing guidelines, avoided public transportation as much as possible, stayed at home/worked from home if possible, and kindergartens/primary schools remained open while secondary schools and higher education institutions were closed. In terms of public places, the government prohibited 
gatherings of more than 50 people, applied restrictions on visits to elderly care homes, and applied restrictions on table service in bars and restaurants.

The Swedish government chose these measures to slow the spread of disease and support the public healthcare system. The government and health authority did not aim to achieve herd immunity or to protect the economy by avoiding a lockdown. They primarily focused on protecting the Swedish people against COVID-19.

However, Sweden has a very high mortality rate and many cases of COVID-19 per 100,000 population, compared to other countries. Notably, most deaths occurred among older people ( $\geq 70$ years of age) who lived in elderly care homes. Because of this severe COVID-19 situation, the government and public health authority have been strongly criticized by other countries and foreign media. In August, while many countries were experiencing a second wave of COVID-19, Sweden did not show clear signs of a second wave and the disease seemed to be spreading more slowly. Regarding the economy, Sweden's gross domestic product will decrease by approximately $10 \%$ in the second quarter of 2020, according to a report issued by the National Institute of Economic Research in Sweden. This decline is expected to be smaller than in other European Union countries. However, similar to other Scandinavian countries, Sweden is small and strongly depends on trade with other countries. When other countries experience an economic crisis due to the COVID-19 pandemic, the Swedish economy is inevitably affected. Thus, an economic downturn is unavoidable, regardless of lockdown implementation or avoidance. Accordingly, this paper examines how the COVID-19 pandemic has affected tourism in Sweden.

\subsection{Tourism in Sweden Before and After the COVID-19 Pandemic}

Sweden has been a member of the European Union since 1995, and has its own currency (Swedish krona). Moreover, Sweden largely adheres to the Schengen Agreement with regard to border control and migration. The population in Sweden is approximately 10 million, which is the highest among Scandinavian countries but smaller than in many other countries worldwide. Notably, Sweden had approximately 7.4 million foreign visitors in 2018. Relative to the number of foreign visitors per population in Japan, inbound tourism is very active in Sweden.

Generally, the peak tourist season is from June to August in Sweden. In total, $71 \%$ of foreign tourists during the summer arrive from Norway, Denmark, Germany, Finland, and the United States. The total profit of the Swedish tourism industry during summer 2019 reached approximately 41 billion Swedish krona. Although Sweden did not apply a nationwide or regional lockdown, its tourism industry profit was reduced by 29 billion Swedish krona in 2020 compared to 2019.

Because many countries have implemented nationwide lockdowns and strongly restricted border control during the COVID-19 pandemic, Swedish tourism has been struggling to survive. Early in the pandemic, Sweden did not close its borders with some countries. However, other countries closed their borders with Sweden and banned their citizens from visiting Sweden. Therefore, the number of foreign visitors dramatically decreased after other countries began to close their borders. 
According to Statistics Sweden, the nationwide occupancy rate of hotel rooms in Sweden was $19.1 \%$ in May 2020, whereas it was 63.4\% in May 2019 [7]. Furthermore, the main air carrier (Scandinavian Airlines) reported only 158,000 passengers in May 2020, a decline of $93.7 \%$ compared to May 2019. Although the aviation industry was severely damaged by the COVID-19 pandemic, the hotel industry still had some domestic business travelers [8].

However, it is difficult to cover the loss of tourism solely by domestic travelers. Regarding the Swedish tourism industry, the government's strategy for the COVID19 pandemic was ineffective for minimizing economic loss, regardless of nationwide or regional lockdowns. ${ }^{2}$ After many countries eased their severe border control restrictions, foreign tourists began gradually to return to Sweden. Scandinavian Airlines reported 705,000 passengers in July 2020, a load factor of 51.0\%. Compared to June 2020, this number was greater by nearly 300,000 , but was 2.5 million lower than in July 2019. Moreover, Scandinavian Airlines reported that the strongest recovery involved domestic flight routes, whereas demand for intercontinental and European flights remained weak. Thus, some time and effort are needed to recover to pre-COVID-19 pandemic levels.

\section{Ethical Concerns and Tourism in the COVID-19 Era}

A core element of tourism is that it is generally regarded as a form of cultural exchange [9]. Traveling to an unfamiliar region and experiencing a completely new culture often provides individuals with an opportunity to reconsider their own cultural backgrounds. The sociologist John Urry described the concept of the "tourist gaze," whereby tourism gives visitors novel interpretations of objects from new perspectives. Tourists bring new interpretations of places, objects, and histories, which differ from local perspectives [10]. Because tourism functions as a form of cultural exchange, there is a risk that cultural differences could cause friction or conflict at actual tourism sites [11].

Modern mass tourism (i.e., package tours) was originally developed by Thomas Cook in England in the nineteenth century. Because it was designed to refresh workers by giving them appropriate vacations, there was no mechanism or impetus to respect the cultures of their destinations. Thus, the behavioral patterns of residents from large cities were brought to more rural locations in a widespread manner. Tourists were often regarded as "golden geese," and the concept of cultural exchange did not manifest in broader tourism until the latter half of the twentieth century. In addition to the traditional structure of mass tourism, hierarchical discrimination against people of non-white ethnicities has persisted due to the historical context whereby Chinese and other Asian people were used as a simple labor force worldwide. This

\footnotetext{
2 Public health problems associated with the lack of a lockdown have also been pointed out recently. Sweden's mortality rate is understandably high, with more than 50 deaths per 100,000 people according to a Johns Hopkins University report released September 24 (see https://coronavirus.jhu.edu/data/morta lity).
} 
has led to a paradoxical discriminatory phenomenon in twenty-first century tourism. Specifically, because tourists from China are customers with substantial financial resources, they should be considered the main target of service. However, the relationships of these customers with potential service providers are not well established because of structural discrimination against people of non-white ethnicities. In Europe and the United States, mass tourism shrank in the latter half of the twentieth century, and the mainstream tourism became more focused on individual travelers. In contrast, due to language and visa challenges, group travel has been the mainstay for Chinese visitors to Europe. Notably, frustration with large numbers of Chinese tourists has often been reported in European tourist destinations [12].

An important example in which tourism causes ethical concerns is the cultural friction triggered by groups of Chinese tourists in foreign countries. China has sent large numbers of tourists to foreign countries in recent years. However, many countries require Chinese tourists to secure tourist visas prior to their trip. These tourists frequently join a group tour and visit foreign countries as a tourist group. They bring considerably activity to their travel destinations, and behave as if they are still in China. Local residents and non-Chinese tourists have complained that the hurried nature of Chinese tourists negatively impacts the atmospheres of travel destinations. These criticisms against Chinese tourists have been increasing in both European and Asian countries, because overseas tourism has become very popular among Chinese people. Although tourism is important for understanding cultural differences, it can occasionally trigger cultural clashes. These days, tourists are asked to be polite in tourism settings, a concept referred to as "responsible tourism". Responsible tourism is a recent concept in the new age of tourism. According to this principle, tourists are asked to behave in such a manner that upholds their social responsibility to others [13].

Groups that promote tourism, including the World Tourism Organization, have suggested that tourism can aid the achievement of world peace. They have also proposed that global mobility facilitates exchange and cooperation, which enhances mutual understanding. However, some tourists intrusively bring their own cultures to travel destinations and cause cultural friction.

Major concerns in cultural friction involve incidents, such as racial or ethnic discrimination. Tourism is not aimed at causing negative social impacts. However, there is considerable risk that tourism serves as a mechanism to breed discrimination. Given that tourism is intended to facilitate mutual understanding through international cultural exchange, the COVID-19 pandemic has led to ethical concerns in tourism. In this section, we discuss global COVID-19-related discrimination, then closely examine the current situations in Japan and Sweden.

\subsection{Global Overview and COVID-19}

According to the World Health Organization, severe acute respiratory syndrome coronavirus 2 was first encountered in Wuhan, China, in December 2019 [14]. The resulting disease, COVID-19, rapidly spread and caused a worldwide pandemic. The virus was first encountered at a meat market in Wuhan, and presumably originated 
from wild animals. It then spread rapidly from Wuhan to all parts of China. Travelers to China (mainly Wuhan) carried the virus into foreign countries with them, such that the disease quickly spread worldwide. Because of this severe disease status, the World Health Organization officially declared a state of Public Health Emergency of International Concern on 30 January, 2020 [15].

Shortly after many patients were diagnosed with COVID-19 in China, the center of the epidemic moved from China to Europe, and then to the United States. In Italy, the first diagnosis of COVID-19 was confirmed in Milan at the end of January 2020, in a Chinese tourist. Subsequently, local residents became seriously ill with COVID19 [16]. The disease then spread exponentially throughout the country, which led to great strain on the healthcare system [17].

During the outbreak of COVID-19, discrimination against Chinese individuals became very serious in Italy [18]. Importantly, people in many Western nations cannot clearly discern between Chinese individuals and other individuals of Asian ethnicity. Therefore, all individuals of Asian ethnicity living in Western world began to experience discrimination, regardless of their nationality [19, 20].

Although COVID-19 began to spread throughout the United States in March 2020, the United States government took prompt action in response to the extremely serious situation in China. The Trump administration banned visitors from China after 31 January 2020 [21]. However, COVID-19 spread from Europe to the United States, beginning in February. Therefore, the ban was extended to visitors from Europe (except the United Kingdom) on 12 March 2020 [22]. A series of hostile attitudes and policies toward China intensified existing discrimination against individuals of Asian ethnicity throughout the United States ${ }^{3}$ [23, 24].

These observations indicate that the COVID-19 pandemic has damaged people's health and livelihood, as well as their societies and communities. It has triggered and intensified racial discrimination against individuals of Asian ethnicity. As mentioned earlier in this section, the core value of tourism is considered the drive to improve mutual understanding globally. However, in the COVID-19 pandemic, tourism has exposed and accelerated discrimination, thereby functioning in a negative manner. When developing a tourism strategy after the COVID-19 pandemic, it will be important to consider discrimination and xenophobia at travel destinations more carefully. It is likely to be insufficient to provide mental support alone. In this regard, Sect. 4 will investigate how ICTs can correct discrimination.

\subsection{Coronavirus Discrimination in Japan}

Japan and China are both geographically located in East Asia. Importantly, most Japanese people have Asian features. For Japanese individuals, it is difficult to distinguish between Japanese and Chinese ethnicities by appearance alone. Therefore, it is unlikely that discrimination based on Asian appearance (as in Western countries) happens in

\footnotetext{
3 The Trump administration's hostile policy toward China is not merely related to the pandemic but also include is a wide range of hard-line stances on China, including the shutdown of Huawei over high-speed $5 \mathrm{G}$ communications.
} 
Japan. However, COVID-19 has aroused considerable fear in people and led to a new type of discrimination in Japanese society.

This new type of discrimination is called Korona Sabetsu (coronavirus discrimination). It has been directed toward individuals with COVID-19 nationwide. A prominent example involved a woman in Toyama prefecture, who graduated from a university in Kyoto prefecture in March 2020. She was then hired to work in her hometown in Toyama. However, she had become ill with COVID-19 in Kyoto, prior to relocation to Toyama. Consequently, she introduced COVID-19 to her hometown and spread the disease to local residents. The people in Toyama had considerable fear of COVID-19 and attempted to identify the source individual. The woman was easily identified and much of her personal information was exposed through social media [25]. Thus, the woman and her family were harassed by local residents. This instance of coronavirus discrimination involved substantial violation of human rights. The Toyama prefectural authority expressed serious concern for a series of slanderous postings on the Internet regarding individuals with COVID-19 [26]. The authority eventually issued a prefectural warning to cease defamation of those patients and their families. Notably, these types of attacks caused relatives and family members to move from their hometowns.

Furthermore, coronavirus discrimination has been directed at individuals who travel from urban areas to rural areas, regardless of their disease status. Another type of discrimination has been directed against non-local residents, especially urban migrants. Because COVID-19 is easily transmitted by airborne virus-containing droplets and close contact, urban areas with high population density and high mobility inevitably have a higher risk of disease than rural areas. Accordingly, unless the mobility of people is carefully controlled, the disease inevitably spreads to rural areas, concomitant with the flow of people from urban areas. In this context, local residents in rural areas have been afraid to have visitors from urban areas. In some rural regions (as noted earlier in this paper), the local people attack and damage cars with non-local license plates, with the aim of frightening the visitors away [27].

These two types of social exclusion interactions function based on the traditional Japanese mechanism of discrimination against outsiders. This mechanism is known as Murahachibu (村八分) in Japanese. It was originally designed to defend local communities against individuals who do not follow traditional customs or rules [28]. However, this mechanism has resulted in power structures whereby unfavorable individuals can be excluded from communities. The residents' severe condemnation of individuals with COVID-19 and the accompanying exclusionary atmosphere both share traditional discriminatory mechanisms. These exhibit similarities with witch-hunting in Western nations and traditional Murahachibu in Japan. However, exclusion in rural Japan has become a form of entertainment, similar to bullying. From an economic perspective, the exclusionary mechanism against outsiders poses a considerable challenge for economic recovery through tourism.

\subsection{Amplified Discrimination in Sweden}

As mentioned in the previous section, Sweden did not apply very severe restrictions to the daily life of its citizens. Discrimination in Sweden differs considerably from 
the situation in Japan. There have been no restrictions on movement or requests for self-restraint (as in Japan). Therefore, Sweden is relatively tolerant of movement from urban areas to rural areas, and there has been no confirmed harassment of people from urban areas.

That said, Sweden is part of Western society. Thus, there has been a link between fear of COVID-19 and the presence of racial discrimination, as observed in Italy and the United States. Initially, Chinese people were the focus of discrimination [29]. However, because many individuals of Asian ethnicity could not be clearly distinguished, all were frequently the focus of discrimination tactics. Therefore, simply increasing the number of people entering the country might be insufficient to achieve a tourism goal, and the problem will not be resolved unless the hosts' discriminatory attitudes are removed.

My proposal is an attempt to identify hidden problems in tourism and to promote tourism and eliminate discrimination at the same time, which is ratheer difficult in practice. However, the spread of COVID-19 has revealed profound discriminatory biases among people. Therefore, considering discrimination in the tourism scene, which has not received close attention thus far, it will be of substantial importance in new tourism-related innovations.

Incidentally, you may be thinking that Swedes also comply with government requirements without legal restrictions.However, although this cultural phenomenon looks the same at first glance, in the case of Japan, compliance derives from an invisible sympathetic pressure based on a fear of exclusion, whereas Sweden's compliance is based on trust in the government. Thus, their origins are, in fact, different [30].

\subsection{Contrast Between Japan and Sweden}

The discrimination in Japan with respect to COVID-19 is directed against affected people and their relatives, or those who move from urban areas, while in Sweden it manifests as discrimination against Chinese people and other individuals of Asian ethnicity. However, because people in both nations have a perceived fear of contracting the disease, tourists will be welcomed if they can confirm that they have no connection to the disease. Based on these assumptions, the next section will look specifically at how ICT can be used in the tourism scene, in the COVID-19 era.

\section{Practical Application of ICT}

In this section, we discuss how to promote tourism while countering COVID-19 discrimination through the use of ICT. Specifically, we refer to the use of locationbased games and COVID-19 contact confirmation applications, and the sustainability of these applications. The location-based game is taken as an example to prevent people gathering. The contact tracing app is considered a secure granting system linked with PCR. 


\subsection{Utilization of location-based games}

There are many possible routes of COVID-19 transmission. However, a high density of people is known to create suitable conditions for transmission. Therefore, it is important to maintain social distancing (i.e., physical distancing) [31]. This is indicated by boundaries in supermarkets and other locations, to aid in adherence to the distancing guidelines [32].

However, such density might be avoided quite easily using ICT. Pokémon Go is an example of a large number of people gathered in a real place on a certain date. The important consideration of the so-called "festival" of Pokémon Go is that neither the people nor the objects in the game are visible in the real world. Traditionally, famous celebrity shows, or new product announcement shows have been used to attract people to events. A typical event is the Meeting and Incentive Conference Exhibition in Las Vegas, which weekday visitors attend for entertainment and trade shows, rather than casinos. In contrast, Pokémon Go allows people to move without interventions from real people and things. An example is as follows: if a rare monster is known to appear in the middle of the desert at a specific time, users will gather there regardless of the cost. An example of successful strategic attraction in Pokémon Go involved the reconstruction of the Great East Japan Earthquake in Ishinomaki City, Japan. Many visitors attended this location because of the possibility of finding rare Pokémon monsters [33]. It may seem contrary to the goal of social distancing in the COVID-19 era for visitors to be concentrated, but a notable feature of the game is that the monsters available for meeting can be easily modified according to the user attributes. By changing the monsters that can be met depending on the level of the user and the team to which the user belongs, it is possible for the company to control how many people are called to which place and when. If the company uses this function in a strategic manner, it can change a "dense" distribution to a "dispersed" distribution.

Advanced research regarding the use of location-based systems to control human behavioral trajectories existed in the early years of the twenty-first century. It was known as SpaceTag [34], which was intended to function as a coupon ticket that was distributed only at a certain place for a certain time, using a Global Positioning System logger. Distribution of these coupons was expected to control pedestrian traffic. Unfortunately, there were no smartphones in this era, so a new device was needed to provide electronic coupons to individual customers. This idea was not widely implemented at the time. However, many people currently have smart phones (i.e., sophisticated receivers). In large shopping malls, such as Carrefour, coupons for store entry could be issued electronically based on location and time, which would enable customers to buy things in a manner that avoids crowding.

Discrimination against people who are or might be infected with COVID-19 could be tolerated by society because of the general fear of the disease. However, in a society where physical distance is managed, there would be less fear of individuals of Asian ethnicity, who are presumed to be "carriers." Discrimination is visible in unstable situations, as demonstrated by the activities of Nazi Germany in the 1930s. Thus, it is also possible to create a society in which the sense of discrimination is less likely to be amplified by correcting social instability. Hitler's speeches 
described a senseless disdain for Jews in the mid-1920s and beyond, but were only accepted by a small number of people before the Great Depression [35]. After the Great Depression, Hitler's speeches rapidly grew in popularity, which indicated that the social instability had led to increased unrest and discrimination. Accordingly, creation of a mechanism to ameliorate social instability can contribute to reduction of discrimination. This might be realized by social distancing using ICT. This will ameliorate the fear of COVID-19 on a local basis, thereby reducing the likelihood of discrimination, and will aid in direct tourism promotional efforts.

\subsection{Ethics of Contact Tracing Apps}

Since the beginning of the COVID-19 epidemic, health technologies have been developed worldwide. An important technology involves identifying the contacts of affected people (i.e., contact tracing). Recently, more and more countries have been able to adopt this technology [36]. In general, this technology is based on the use of smart phones; Sweden has taken a different approach to this technology compared to other countries. In this section, we first discuss the technology used by Japan, then compare it with the technology used by Sweden.

The Japanese contact tracing app was developed by the Ministry of Health, Labor and Welfare and is available to citizens via the App Store (iPhone) and Google Play Store (Android). Its installation is not required nationwide. As of 7 August 2020, there were only 1.25 million downloads [37]. The usage is simple and assumes that the person who downloads the app will keep Bluetooth functionality on. When a person receives a positive test result, the person registers in the application. Based on information linked to the server, the app will warn individuals around the person with COVID-19 that they had contact with an affected person. Because there is no enforcement mechanism, the app is not actively used in Japan and its effectiveness is highly questionable.

In contrast, Sweden stopped the design of a tracking app in its early development. This was to protect the privacy of Swedish citizens, and prohibited the state from publicly tracking the spread of COVID-19 [38]. It is useful to consider the potential impact of the app on the discrimination issue discussed in this paper, if the app had been successful. This app would have been an important technological development for anti-racism purposes. Thus far, Chinese individuals have rarely been a distinct group in Sweden, and the use of contact apps would presumably have reinforced this trend by indicating that Chinese/Asian individuals are not a significant source of COVID-19 spread.

Now, we consider the significance of this app in Japan from a sociological point of view. In practice, there have been few installations of the app, so this is a speculative theory. If the app had been broadly successful, it could have caused increased discrimination in rural Japan, unless strict privacy control had been implemented. As explained in Sect. 2, discrimination in Japan is caused by the concern that urban residents will spread disease to rural areas. If an employee in a tourist area were to receive an alert through the app, rumors regarding the danger of urban tourists might spread. As of early August 2020, the spread of COVID-19 in Japan was from 
urban areas to rural areas. As previously mentioned, at the core of discrimination is fear of the unfamiliar, which is amplified in the COVID-19 era. For the prevention of discrimination, it might become necessary to use the contact tracing app to convince people that unfamiliar individuals nearby are not dangerous.

To use a contact tracing app to reduce discrimination, there is a need to shift toward "informing healthy individuals" rather than "informing people with COVID19". Notably, most app users in Japan have been informed that they have not been near an individual with COVID-19, which is reassuring information. If the negative results of each person's most recent polymerase chain reaction test were incorporated into this system and transmitted to people nearby, this reassurance might reduce attribute-based discrimination. Because this approach has already been introduced in the context of arrivals at international airports, public rejection of the system would presumably be minimal [39]. Regarding people with COVID-19, because segregation is legalized in Japan, it is unlikely that those people would encounter difficulties in restaurants and tourist facilities.

The contact tracing app was originally developed to identify clusters of people with COVID-19, but users are more likely to install the system to achieve reassurance. This valuable system could be used to reduce discrimination and promote tourism.

\subsection{Overcrowding and Sustainability}

In Sect. 4, the utility of location information games (e.g., Pokémon Go) and contact tracing applications were considered. These two technologies will be important in solving the problem of "overcrowding" in tourism. In recent years, over-tourism has been identified as a problem in the tourism scene. Over-tourism refers to the presence of tourists beyond the capacity of the tourist destination. This has been described in Kyoto and Barcelona, where residents' lives are threatened by large numbers of tourists [40, 41]. Over-tourism has a wide range of associated challenges. If a large number of people simultaneously enter a single building, the damage to that building might be severe. For example, at the World Heritage site of Himeji Castle, the number of visitors to the castle tower is limited to alleviate congestion and reduce damage to the building [42]. In the context of ecotourism, this phenomenon of over-tourism is particularly problematic. Accordingly, the World Natural Heritage Site of the Ogasawara Islands is attempting to preserve the natural environment by limiting the number of visitors to areas where vegetation is vulnerable [43]. Importantly, a Pokémon Go event was held in the Tottori Dunes, which players enjoyed because it was a large sand dune environment. However, this was found to have a substantial impact on the dune biodiversity [44]. The large number of people trampled the sand, placing a serious strain on the natural environment and preventing plants from sprouting.

To solve these problems, tourists must be appropriately distributed, which coincides with measures to prevent disease spread. As mentioned above, it is important to avoid "overcrowding" to enable the control of disease spread. This can also contribute to controlling over-tourism and the effective use of tourism resources. 


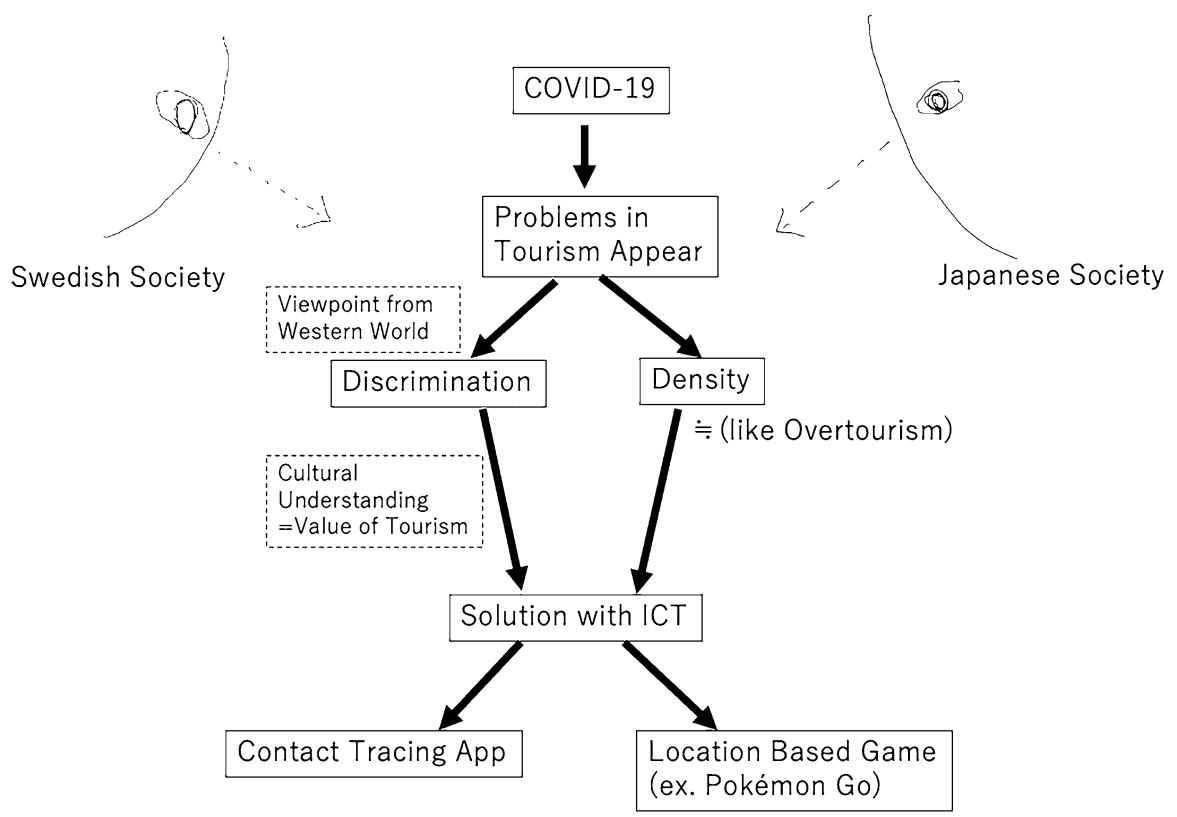

Fig. 1 Total idea of this paper

The combination of a merit system (e.g., a coupon) as in a location information game, as well as technology that traces tourists' activities, will enable suitable numbers of tourists to attend specific places at appropriate times. Eventually, this approach might reduce the tourist load on the area, including its natural environment, thereby facilitating sustainability. The applicability of this approach to COVID-19 may be limited, but these behavioral changes may support the development of new sustainability methods.

\section{Conclusion and future work}

We have discussed the current state of tourism industries in Japan and Sweden. We have also discussed the discrimination that has emerged in relation to tourism during the COVID-19 pandemic, along with the ICT that can be used to resolve this problem. Regarding the response to COVID-19, the cultural foundations of the two countries are quite different and it may be difficult to identify many common aspects. However, we were able to consider the application of ICT in the two countries. We expect that the influence of COVID-19 on tourism will be further explored in the future, and we hope that this paper can serve as an initial contribution to the academic community.

Many keywords and concepts are included in this paper. Figure 1 shows the overall idea of the paper. By viewing Fig. 1 will facilitate understanding of the text of this paper. 
Finally, this paper has certain limitation and indicates areas of future work. This study deals with only two possibilities: a contact-tracing app and Pokémon Go. Many types of contact tracing apps are available. In this paper, a human-based type of contact tracing app is discussed. Future research should analyze location-based contact tracing applications. Moreover, based on the discussion of Pokémon Go, I would like to extend the knowledge gained from this research to location-based games in general.

Acknowledgement Special thanks to Dr. Rryoco Asai. This study was supported by the JSPS/STINT Bilateral Joint Research Project "Information and Communication Technology for Sustainability and Ethics: Cross-national Studies between Japan and Sweden" (JPJSBP120185411) and by JSPS KAKENHI Grant Numbers JP18K18441, JP 18K11860, JP18K12000, JP18K11886, JP20H01220.

\section{References}

1. Corona by Country. (2020). $<<$ New corona, preventing spread of infection $>>$ Sakaimachi 87 restaurants and restaurants closed closed on 19 th when requested by the town. Coronavirus articles about Japan on 2020-04-13. https://coronabycountry.com/en_US/Japan/2020/04/13. Accessed 29 September 2020.

2. Ministry of Finance. Total value of exports and imports (1950-) - trade statistics of Japan https:// www.customs.go.jp/toukei/suii/html/nenbet_e.htm Accessed 29 September 2020.

3. Ministry of Land, Infrastructure, Transport and Tourism. (2007). White paper on tourism in Japan, 2007 (Summary). https://www.mlit.go.jp/common/000221172.pdf. Accessed 29 September 2020

4. Japan Tourism Agency. (2019). White paper on tourism in Japan, 2019 (Summary). https://www. mlit.go.jp/kankocho/en/siryou/content/001312296.pdf. Accessed 29 September 2020.

5. Japan National Tourism Organization(JNTO). (2020). 2020 Visitor arrivals and Japanese overseas travelers. Press release. https://www.jnto.go.jp/jpn/statistics/data_info_listing/pdf/200715_month ly.pdf. Accessed 29 September 2020.

6. Kyodo News. (2020). Online debate erupts over "coronavirus evacuation". Article https://engli sh.kyodonews.net/news/2020/04/da340fb858de-feature-online-debate-erupts-over-coronaviru s-evacuation.html. Accessed 18 January 2021.

7. Statistics Sweden. (2020). Number of available rooms and occupancy rate, revenue per occupied room for hotels, by region/county. Preliminary statistics. Month 2008M01-2020M07/. Database http://www.statistikdatabasen.scb.se/pxweb/en/ssd/START__NV__NV1701_NV1701B/NV170 1T7M/. Accessed 29 September 2020.

8. Scandinavian Airlines System. (2020). SAS traffic figures-April 2020. Press release. https://www. sasgroup.net/newsroom/press-releases/2020/sas-traffic-figures---april-2020/. Accessed 29 September 2020 .

9. Organisation for Economic Cooperation and Development (OECD). (2009). The impact of culture on tourism. OECD publishing.

10. John Urry, J., \& Larsen, J. (2011). The Tourist Gaze 3.0. SAGE Publications Ltd.

11. World Tourism Organization (UNWTO). (2017). Annual Report 2016. World Tourism Organization (UNWTO).

12. BBC. (2013). Chinese tourists warned over behaviour abroad. Article https://www.bbc.com/news/ world-asia-china-22573572. Accessed 29 September 2020.

13. Lee, H., Bonn, M., Reid, E., \& Kim, W. (2017). Differences in tourist ethical judgment and responsible tourism intention: An ethical scenario approach. Tourism Management, 60, 298-307.

14. World Health Organization (WHO). (2020). Pneumonia of unknown cause-China. Disease outbreak news. https://www.who.int/csr/don/05-january-2020-pneumonia-of-unkown-cause-china/en/. Accessed 29 September 2020.

15. World Health Organization (WHO). (2020). Statement on the second meeting of the International Health Regulations (2005) Emergency Committee regarding the outbreak of novel coronavirus (2019-nCoV).Statement https://www.who.int/news-room/detail/30-01-2020-statement-on-the-secon 
d-meeting-of-the-international-health-regulations-(2005)-emergency-committee-regarding-theoutbreak-of-novel-coronavirus-(2019-ncov). Accessed 29 September 2020.

16. BBC. (2020). Coronavirus: Italy death toll tops 30,000, highest in EU. News. https://www.bbc.com/ news/world-europe-52594570. Accessed 29 September 2020.

17. The New York Times. (2002). Italy's Health Care System Groans Under Coronavirus - a Warning to the World. Article. https:/www.nytimes.com/2020/03/12/world/europe/12italy-coronavirus-healt h-care.html. Accessed 29 September 2020.

18. ANSAenEnglish. (2020). Italian teen set to return from Wuhan. Article. https://www.ansa.it/english/ newswire/english_service/2020/02/14/ansa-italian-teen-set-to-return-from-wuhan_0079c12f-fba34932-88bb-371a7ef793a0.html. Accessed 29 September 2020.

19. Burke, C. (2020). Racist 'corona time' photo of students in asian costumes prompts outcry. News. Heavy. https://heavy.com/news/2020/03/racist-corona-time-photo-students-belgium/. Accessed 29 September 2020.

20. Cava, M., \& Lam, K. (2020). Coronavirus is spreading. And so is anti-Chinese sentiment and xenophobia. USA Today. https://www.usatoday.com/story/news/nation/2020/01/31/coronavirus-chinesexenophobia-racism-misinformation/2860391001/. Accessed 29 September 2020.

21. Donald Trump. (2020). Proclamation on suspension of entry as immigrants and nonimmigrants of persons who pose a risk of transmitting 2019 novel coronavirus. https://www.whitehouse.gov/presi dential-actions/proclamation-suspension-entry-immigrants-nonimmigrants-persons-pose-risk-trans mitting-2019-novel-coronavirus/. Accessed 29 September 2020

22. Schengenvisainfo. (2020). Trump bans nationals of 26 European countries from entering US. News. https://www.schengenvisainfo.com/news/trump-bans-nationals-of-26-european-countries-fromentering-us/.Accessed 29 September 2020.

23. NBCNEWS. (2020). Asian Americans report over 650 racist acts over last week, new data says. News. https://www.nbcnews.com/news/asian-america/asian-americans-report-nearly-500-racis t-acts-over-last-week-n1169821. Accessed 29 September 2020.

24. EYETIMESS. (2020). Where's your (expletive) mask?': Asian woman attacked in Manhattan hate crime. News. https://abc7ny.com/6003396/. Accessed 29 September 2020.

25. Ha, L. (2020). Discrimination and stigma in Japanese society: The case of COVID-19. Article. Izanau https://izanau.com/article/view/coronavirus-discrimination-japan. Accessed 29 September 2020

26. Toyama Prefecture. (2020). Consideration for human rights related with new coronavirus infection(in Japanese). Statement. http://www.pref.toyama.jp/cms_sec/1711/kj00021811.html. Accessed 29 September 2020.

27. Japan Federation of Bar Association. (2020). <COVID-19>statement calling for building a society without discrimination in the midst of the COVID-19 pandemic, statement. https://www.nichibenre n.or.jp/en/document/statements/200729.html. Accessed 29 September 2020.

28. Ukai, N. (1953). Japanese election results reconsidered. Pacific Affairs, 26(2), 139-146.

29. The Local. (2020). We experienced a racist assault for wearing face masks in Stockholm. Article. https://www.thelocal.se/20200520/we-experienced-a-racist-assault-for-wearing-face-masks. Accessed 29 September 2020.

30. Braw, E. (2020). What Sweden can teach us about coronavirus, Articles. Politico. https://www.polit ico.eu/article/sweden-coronavirus-lessons/. Accessed 19 January 2021.

31. Sun, C., \& Zhai, Z. (2020). The efficacy of social distance and ventilation effectiveness in preventing COVID-19 transmission. Sustainable Cities and Society, 62, 102390.

32. Storac, R. (2020). As COVID-19 continues, more and more consumers turn to online grocery shopping, News. GlobeSt. https://www.globest.com/2020/05/06/as-covid-19-continues-more-and-moreconsumers-turn-to-online-grocery-shopping. Accessed 29 September 2020.

33. Gasparri, D. (2019). Locals, new-locals, non-locals .doctoral dissertation. Oxford Brookes University. https://www.researchgate.net/profile/Duccio_Gasparri/publication/342354524_Locals_Newlocals_Non-locals_Remapping_people_and_food_in_post-disaster_Ishinomaki_Japan/links/5ef07 611a6fdcc73be943c4f/Locals-New-locals-Non-locals-Remapping-people-and-food-in-post-disasterIshinomaki-Japan.pdf.Accessed 29 September 2020.

34. Tarumi, H., Morishita, K., Nakao, M., \& Kambayashi, Y. (1999). SpaceTag: An overlaid virtual system and its applications. Proceedings IEEE International Conference on Multimedia Computing and Systems, 1, 207-212.

35. Baranowski, S. (2011). Nazi empire: German colonialism and imperialism from Bismarck to Hitler. Cambridge University Press. 
36. Ramanm, M. (2020). Here are the countries using Google and Apple's COVID-19 contact tracing API , Articles, XDA, Accessed 19 January 2021.

37. Ministry of Health, Labor and Welfare. (2020). Request to install the COVID-19 Contact-Confirming Application. Resource document. Office for Novel Coronavirus Disease Control National Strategy Office of Information and Communication Technology. https://corona.go.jp/prevention/pdf/ en.cocoa.pdf.Accessed 29 September 2020.

38. Stv Nyheter. (2002). Forskare varnar för corona-appar (in Swedish). Articles. https://www.svt.se/ nyheter/utrikes/forskare-varnar-for-corona-appar. Accessed 29 September 2020.

39. Kim, J. Y., Choe, P. G., Oh, Y., Oh, K. J., Kim, J., Park, S. J., \& Oh, M. D. (2020). The first case of 2019 novel coronavirus pneumonia imported into Korea from Wuhan, China: implication for infection prevention and control measures. Journal of Korean medical science, 35(5).

40. Milano,C., Cheer, J.M., \& Novelli, M. (2018). Overtourism: a growing global problem. The Conversation, 18. https://theconversation.com/overtourism-a-growing-global-problem-100029. Accessed 29 September 2020.

41. Martins, M. (2018). Tourism planning and tourismphobia: An analysis of the strategic tourism plan of barcelona 2010-2015, Journal of Tourism, Heritage \& Services Marketing, 4 (1) 1,3-7.

42. Himeji Castle, Frequent asked questions. https://www.himejicastle.jp/en/faq.html. Accessed 29 September 2020.

43. Forest Agency. Request for protecting nature in Ogasawara Islands(in Japanese). Statement. https:// www.rinya.maff.go.jp/j/sin_riyou/sekaiisan/ogasawara_onegai.html. Accessed 29 September 2020.

44. Tsurusaki, N., et al. (2018). Abrupt decrease of the population of a tiger beetle species, Cylindela elisae (Carabidae, Cicindelinae), in Tottori Sand Dunes, Honshu, Japan in 2017. Natural History Research of San'in, 15, 7-14.

Publisher's Note Springer Nature remains neutral with regard to jurisdictional claims in published maps and institutional affiliations. 